\title{
Endoscopic ultrasound-guided duodenojejunostomy for management of refractory benign hepaticojejunal anastomotic stricture
}

A 45-year-old man was referred to our endoscopy unit because of a benign refractory hepaticojejunal anastomotic stricture. Previous transhepatic anastomotic dilations had failed to guarantee longterm patency. We proposed endoscopic ultrasound (EUS)-guided duodenojejunostomy created using a lumen-apposing metal stent (LAMS) to allow endoscopic management of the bilioenteric stricture. The efferent limb was filled with water and contrast medium from the percutaneous biliary transhepatic drainage (PTBD) ( $\triangleright$ Fig.1 a,b). Then under EUS guidance, a LAMS (Hot-Axios, $10 \times$ $15 \mathrm{~mm}$ ) was deployed from the duodenal bulb into the target jejunal loop, using pure cut effect 4. A long 0.025-inch guidewire was coiled inside the loop. Under fluoroscopic and endoscopic guidance both flanges of the LAMS were successfully deployed without complications ( $\triangleright$ Video 1 ).

In the same session, a fully covered selfexpandable metal stent (FCSEMS) (Wallflex; Boston Scientific) was deployed across the stenosed bilioenteric anastomosis ( $\mathbf{F i g}$. 2).

The patient started on an oral diet the same day and he was discharged on day 1. At 6-month follow-up, upper endoscopy was performed with easy passage through the LAMS to remove the FCSEMS. Subsequent evaluation highlighted a good patency of the anastomosis with no secondary biliary stones ( Video 1).

At 9 months after the EUS-guided duodenojejunostomy and 3 months from FCSEMS removal the patient is asymptomatic with normal liver test results. The LAMS is still in place.

Benign stricture may occur in up to $24 \%$ of cases after bilioenteric anastomosis [1], and PTBD is the gold standard treatment. EUS-guided anastomosis using a LAMS is becoming standardized in tertiary centers, for cholecystogastrostomy,
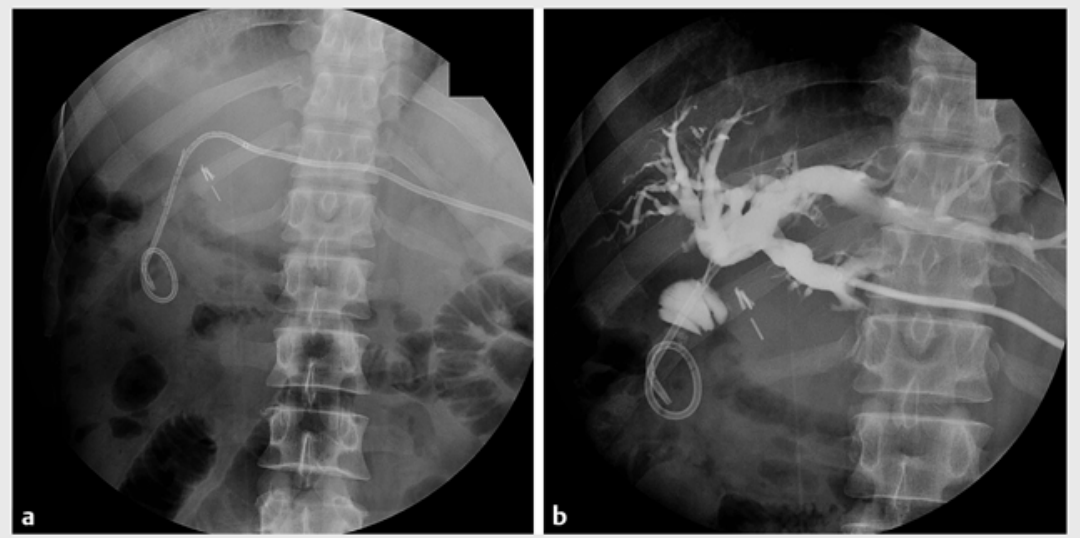

- Fig. 1 a Percutaneous biliary transhepatic drainage (PTBD) in a patient with a benign refractory hepaticojejunal anastomotic stricture. b Contrast medium delivered via the PTBD, showing the bilioenteric anastomotic stricture and filling of the efferent jejunal loop.

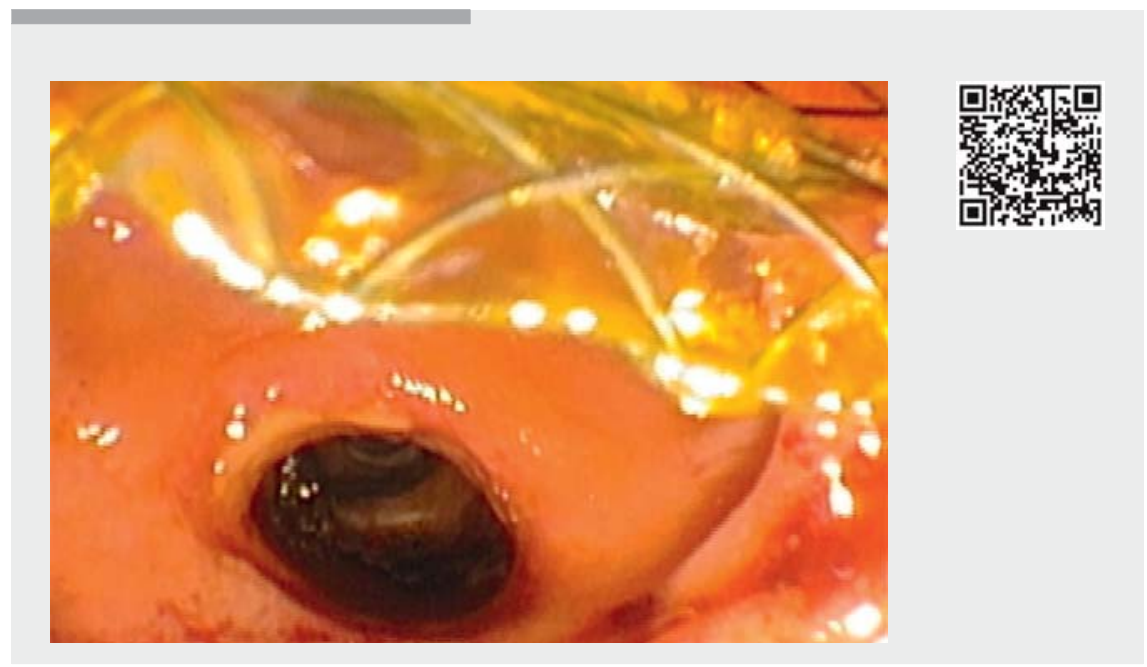

$\square$ Video 1 Endoscopic ultrasound (EUS)-guided duodenojejunostomy created using a lumen-apposing metal stent (LAMS) to enable endoscopic management of a bilioenteric anastomotic stricture. The duodenojejunostomy allowed delivery of a fully covered self-expandable metal stent (FCSEMS) across the stricture in the same session.

gastrojejunal anastomosis, and in cases of altered anatomy [2,3].

We report one of the first cases of EUSguided duodenojejunostomy where a prior PTBD was used to fill the target jejunal loop with water and contrast medium.
Direct EUS-guided transgastric hepatic injection in order to fill the jejunal loop is another viable option that would allow a single-operator single-session procedure. 


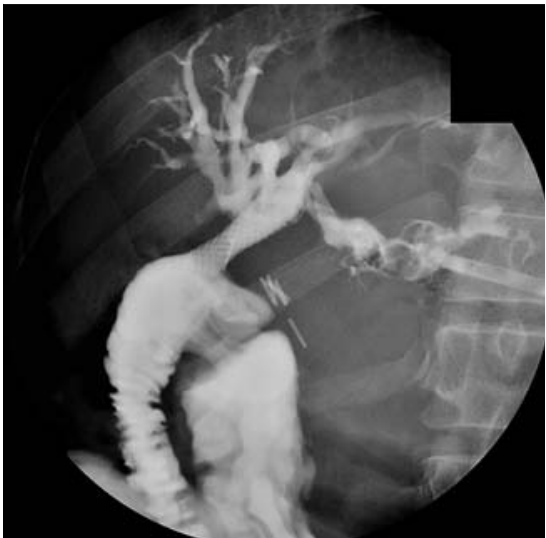

Fig. 2 Fluoroscopy showing the lumenapposing metal stent (LAMS) and the fully covered self-expandable metal stent (FCSEMS) in place, with contrast opacification of the biliary tree, the efferent jejunal loop, and the stomach.

Permanent duodenojejunostomy using a LAMS seems a feasible and safe technique for the management, of bilioenteric anastomotic stricture in selected cases.

Endoscopy_UCTN_Code_TTT_1AS_2AD

\section{Competing interests}

The authors declare no conflict of interest.
Gianfranco Donatelli ${ }^{1}$, Fabrizio Cereatti ${ }^{2}$, Serge Derhy ${ }^{3}$

1 Unité d'Endoscopie Interventionnelle, Hôpital Privé des Peupliers, Ramsay Générale de Santé, Paris, France

2 Gastroenterologia ed Endoscopia Digestiva ASST Cremona, Cremona, Italy

3 Unité de Radiologie Interventionnelle, Hôpital Privé des Peupliers, Ramsay Générale de Santé, Paris, France

\section{Corresponding author}

\section{Gianfranco Donatelli, MD}

Unité d'Endoscopie Interventionnelle, Ramsay Générale de Santé, Hôpital Privé des Peupliers, 8 Place de l'Abbé G. Hénocque, 75013, Paris, France Fax: + 33-1-44165615

donatelligianfranco@gmail.com

\section{References}

[1] Dimou FM, Adhikari D, Mehta HB et al. Incidence of hepaticojejunostomy stricture after hepaticojejunostomy. Surgery 2016; 160: $691-698$

[2] Jacques ], Privat J, Pinard F et al. Endoscopic ultrasound-guided choledochoduodenostomy with electrocautery-enhanced lumenapposing stents: a retrospective analysis.
Endoscopy 2018. doi:10.1055/a-0735-9137 [Epub ahead of print]

[3] Jain D, Chhoda A, Sharma A et al. De-novo gastrointestinal anastomosis with lumen apposing metal stent. Clin Endosc 2018; 51: 439-449

\section{Bibliography}

DOI https://doi.org/10.1055/a-0896-2310

Published online: 9.5.2019

Endoscopy 2019; 51: E261-E262

(c) Georg Thieme Verlag KG

Stuttgart · New York

ISSN 0013-726X

\section{ENDOSCOPY E-VIDEOS}

https://eref.thieme.de/e-videos

回发 Endoscopy E-Videos is a free

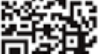
access online section, reporting on interesting cases and new techniques in gastroenterological endoscopy. All papers include a high quality video and all contributions are freely accessible online.

This section has its own submission website at https://mc.manuscriptcentral.com/e-videos 